\title{
Acute effects of high-volume compared to low-volume resistance exercise on lung function
}

\author{
Daniel Hackett ${ }^{*}$ \\ Physical Activity, Lifestyle, Ageing and Wellbeing Faculty Research Group, School of Health Sciences, Faculty of Medicine and Health, The University of Sydney, Sydney, \\ Australia
}

The aim of this study was to examine whether a high-volume compared to low-volume resistance exercise session acutely impairs lung function. Fourteen males (age $23.8 \pm 6.5$ years) with resistance training experience participated in this study. Participants completed two resistance training protocols (high- and low-volume) and a control session (no exercise) with the sequence randomised. High- and low-volume sessions involved 5 sets (5-SETS) and 2 sets (2-SETS), respectively of 10 repetitions at $65 \%$ one-repetition maximum for each exercise (bench press, squat, seated shoulder press, and deadlift) with 90 -sec recovery between sets. Lung function was evaulated pre- and postsession and respiratory gases were measured during the recovery between sets of exercises. An increase in the ratio of forced expiratory volume in $1 \mathrm{sec}$ $\left(\mathrm{FEV}_{1}\right)$ to forced vital capacity was found following the 5-SETS compared to 2-SETS $(P=0.033)$. There was a significant reduction in inspiratory capacity following 5 -SETS compared to control session $(P=0.049)$.
No other lung function parameter was affected postsession. During training sessions, the squat and deadlift required greater ventilatory demands compared to the bench press and shoulder press $(P<0.001)$. Across most exercises during 5-SETS compared to 2-SETS, there was a lower end-tidal $\mathrm{CO}_{2}$ partial pressure. Across most exercises during 5-SETS compared to 2-SETS there was a lower end-tidal $\mathrm{CO}_{2}$ partial pressure $\left(\mathrm{PETCO}_{2}\right)(P \leq 0.013)$, although there were no other differences in physiological responses between the sessions. The findings tend to suggest that the ventilatory and respiratory muscle demands of a strenuous resistance exercise session are not great enough to acutely impair indices of lung function.

Keywords: Lung function, Respiratory muscles, Resistance training, Muscle strength, Exercise performance

\section{INTRODUCTION}

Resistance training is an effective exercise modality for increasing muscle strength and mass, which are important components of fitness and health (Bird et al., 2005; Winett and Carpinelli, 2001). To optimize training response requires manipulation of acute training variables (e.g., frequency, intensity, and volume) with careful consideration given to training experience to ensure the program is individualized (Kraemer and Ratamess, 2004). Resistance training volume (sets $\times$ repetitions) is considered to be an important determinant of muscle strength and hypertrophy. Even though increases in muscle strength can be achieved when performing lower-volume resistance training $(<3$ sets per exercise), it appears that higher volume resistance training ( $\geq 3$ sets per ex- ercise) results in larger gains (Krieger, 2009, 2010). Consequently, to maximize muscle hypertrophy it is recommended that higher volume (3-6 sets of 6-12 repetitions) and moderate load (70\%$85 \%$ one-repetition maximum [1RM]) resistance training sessions are prioritized (Ratamess et al., 2009). These training practices are associated with increased metabolic acidosis and ventilatory demand compared to lower-volume resistance training sessions (Kang et al., 2005; Wirtz et al., 2014). The increased physiological demands from higher volume resistance training sessions may lead to adaptations that may enable training with heavier loads for longer (i.e., improved muscle endurance) (Radaelli et al., 2015), thus better session tolerance (e.g., less symptoms of dizziness and nausea) (Kraemer and Ratamess, 2004). Additionally, it seems plausible that higher volume resistance training may induce posi-
*Corresponding author: Daniel Hackett (iD https://orcid.org/0000-0002-2504-3942 Physical Activity, Lifestyle, Ageing and Wellbeing Faculty Research Group, School of Health Sciences, Faculty of Medicine and Health, The University of Sydney,

75 East Street Lidcombe, Sydney, New South Wales, Australia

E-mail: daniel.hackett@sydney.edu.au

Received: September 4, 2020 / Accepted: September 23, 2020
This is an Open Access article distributed under the terms of the Creative Commons Attribution Non-Commercial License (https://creativecommons.org/licenses/by-nc/4.0/) which permits unrestricted non-commercial use, distribution, and reproduction in any medium, provided the original work is properly cited. 
tive changes in lung function. Improved lung function has been shown following resistance training in people with chronic obstructive pulmonary disease (Strasser et al., 2013), however, there is a paucity of research on this topic in apparently healthy populations.

For lung function to be improved following high-volume resistance training it would be expected that lung function parameters would be acutely impaired following a training bout. Such a hypothesis is based on training adaptation theories which suggest that an adequate training stimulus would result in the accumulation of fatigue, which in this case would be a reduction lung function, and upon recovery an improvement in performance (Cunanan et al., 2018). Diminished lung function has been observed following marathon and ultramarathon running (Tiller, 2019) and after a CrossFit (i.e., a form of high-intensity interval training) bout (Shaw et al., 2015). Furthermore, superior lung function performance has been observed in endurance athletes compared to strength and power athletes (Lazovic et al., 2015). This suggests that lung function adaptations from exercise training are dependent on the nature of the exercise (e.g., type, frequency, intensity, and duration). Khosravi et al. (2013) found that changes in lung function parameters following resistance training were minimal compared endurance training. Although, this previous study implemented a resistance training program involving mostly isolated (i.e., single joint) exercises, whereas programs with a greater emphasis on compound (i.e., multi joint) exercises are considered to be more effective for enhancing muscle adaptation and are more commonly used by experienced trainers (Paoli et al., 2017). It should also be noted that compound exercises such as the squats and deadlifts require increased activation of the respiratory muscles such as the diaphragm to assist with spine stability (Martuscello et al., 2013). Therefore, it seems plausible that the increased respiratory muscle work from assisting with spine stability together with elevated ventilation demands from high-volume resistance training would place significant stress on the respiratory system leading to an acute reduction in lung function performance.

To date, no study has investigated whether lung function is acutely affected following physically demanding resistance training sessions. The aim of this study was to examine whether a high-volume compared to a low-volume whole-body resistance exercise session acutely impairs lung function. It was hypothesized there would be evidence of reduced lung function performance following the highvolume compared to low-volume resistance exercise session.

\section{MATERIALS AND METHODS}

This study used a crossover, repeated measures design with random allocation of participants into three sequences (high-volume, low-volume, and control sessions). Fourteen males (age, 23.8 \pm 6.5 years; body mass, $83.2 \pm 7.2 \mathrm{~kg}$; stature, $179.2 \pm 4.3 \mathrm{~cm}$ ) with $4.6 \pm 2.1$ years of resistance training experience participated in this study. Their one-repetition maximum (1RM) was $97.5 \pm 17.1$ $\mathrm{kg}$ for the bench press, $125.5 \pm 18.3 \mathrm{~kg}$ for squat, $59.3 \pm 13.1 \mathrm{~kg}$ for shoulder press, and $139.6 \pm 25.0 \mathrm{~kg}$ for deadlift. The eligibility criteria for this study included being male, aged $18-45$ years, $\geq 1$-year resistance training experience, and having the ability to perform the bench press, shoulder press, squat, and deadlift. The exclusion criteria included asthma, current respiratory illness, medications that could influence lung function and any chronic disease or condition. Verbal and written consent was provided by all participants prior to study commencement. This study was approved by the University of Sydney Human Research Ethics Committee (approval number: 2014/977).

Upon enrolment into the study, participants visited the exercise laboratory to become familiarised with lung function testing which involved performing a minimum of three trials for each measure described below. Based on these initial results all participants were deemed to have normal lung function (Johnson and Theurer, 2014). During the same visit, participants performed 1RM tests for the resistance exercises that were to be performed in the exercise sessions. Following the 1RM testing, each participant was given an opaque sealed envelope which contained a randomly assigned sequence for the three experiment sessions.

\section{Experimental sessions}

Lung function tests were conducted $15 \mathrm{~min}$ prior to beginning the resistance exercises for the low- and high-volume sessions (presession), and 5 min following the completion of these sessions (postsession). Resistance exercise warm-up sets, performed following the respiratory measurements, consisted of 1-2 sets of each exercise at perceived light loads. The control session involved performing the lung function tests, sitting quietly for $50 \mathrm{~min}$, and then repeating these tests. It was estimated that the high- and low-volume resistance exercise sessions would take about 50 and $25 \mathrm{~min}$ to complete, respectively. For the low- and high-volume resistance training sessions participants were required to perform 2 sets (2SETS) and 5 sets (5-SETS) respectively of 10 repetitions (or to failure if unable to reach 10 repetitions in a set) at 65\% 1RM of four exercises (bench press, squat, seated shoulder press, and dead- 
lift) with 90-sec recovery between sets (Ratamess et al., 2009). These exercises were selected because they target most of the major muscle groups and are commonly performed by experienced resistance trainers to maximize muscle adaptations (Ferland et al., 2020). The order in which participants performed these exercises was bench press, squat, shoulder press, and deadlift. Repetitions were performed at a self-determined tempo for the concentric and eccentric phases while performing the exercise through the full range of motion available. During the 90-sec recovery period between sets for each exercise heart rate was measured and respiratory gases were collected. Prior to all experimental sessions' participants were asked to refrain from using caffeine or pre-workout supplements (2-3 hr prior), not eat within $1 \mathrm{hr}$ of the sessions, and avoid any strenuous physical activity in the preceding $24-48 \mathrm{hr}$.

Lung function was assessed via the Medgraphics pulmonary function testing system (Ultima Series $\mathrm{CardiO}_{2}$ and PFX, Medgraphics, Minneapolis, MN, USA). The measures were performed in a standing position, using a nose clip and instructing participants to keep their lips securely around the mouth piece to prevent any air escaping during the tests. Forced vital capacity (FVC) was the first test performed and involved emptying the lungs of air and then fully inspiring, followed by full expiration. The forced expiratory volume in $1 \sec \left(\mathrm{FEV}_{1}\right), 3 \sec \left(\mathrm{FEV}_{3}\right)$, and $6 \sec \left(\mathrm{FEV}_{6}\right)$, ratio of $\mathrm{FEV}_{1}$ to $\mathrm{FVC}\left(\mathrm{FEV}_{1} / \mathrm{FVC}\right)$, inspiratory capacity (IC), and expiratory reserve volume (ERV) were obtained from the FVC. After the FVC, participants performed the slow vital capacity (SVC) test which involved performing a minimum of four stable tidal breaths followed by a maximal inspiration and then a maximal expiration, performed in a slow manner. The final test conducted was the maximal voluntary ventilation (MVV) which involved the participant breathing deeply and rapidly on the command over a period of $12 \mathrm{sec}$. Three trials were performed for FVC, SVC, and MVV with $\geq 30$-sec recovery between trials. The best trial for all measures was used for data analysis.

\section{Physiological measures}

Respiratory gases were continuously measured by breath-bybreath analysis using open circuit spirometry while resting in a seated position between sets of exercises (Ultima Series $\mathrm{CardiO}_{2}$ and PFX, Medgraphics). The respiratory gas measures included oxygen uptake $(\mathrm{mL} / \mathrm{kg} / \mathrm{min})\left(\mathrm{VO}_{2}\right)$, minute ventilation $(\mathrm{VE})$, tidal volume, respiratory rate, and end-tidal $\mathrm{CO}_{2}$ partial pressure (PET$\mathrm{CO}_{2}$ ). Additionally, heart rate measurements (Polar T31, Polar Electro Oy, Kemple, Finland) were recorded during the recovery between sets. The period of gas collection and heart rate measure- ment was for $60 \mathrm{sec}$ and begun within $5 \mathrm{sec}$ of the last repetition of each set. The rationale for only collecting respiratory gases and heart rate measurements during the recovery between sets of exercises was because of the greater responses that occur within this period for resistance training exercises compared to during the actual exercise (Scott, 2011; Scott et al., 2009). Respiratory gas and heart rate responses were averaged over $60 \mathrm{sec}$ for each set due to the nonsteady state nature of the ventilatory and heart rate responses following resistance exercises. The average values for recovery responses for each exercise following completion of the assigned number of sets (i.e., 2 sets vs. 5 sets) were calculated for each participant.

\section{Statistical analyses}

Statistical analyses were performed using IBM SPSS Statistics ver. 24.0 (IBM Co., Armonk, NY, USA). Data were inspected visually and statistically for normality using the Kolmogorov-Smirnov test. For data that were not normally distributed $\log 10$ transformations were performed. Normally distributed data are presented as mean \pm standard deviation and as median with interquartile range for data not normally distributed. A one-way analysis of covariance, with presession lung function as a covariate, was used to assess differences between conditions (2-SETS vs. 5-SETS vs. control) for lung function (FVC, SVC, $\mathrm{FEV}_{1}, \mathrm{FEV}_{3}, \mathrm{FEV}_{6}$, IC, ERV, and MVV). A one-way analysis of variance (ANOVA) was used to assess differences between physiological measures $\left(\mathrm{VO}_{2}, \mathrm{VE}\right.$, tidal volume, respiratory rate, $\mathrm{PETCO}_{2}$, and heart rate) and exercises and between sessions. For significant ANOVA results (for exercise analyses), a post hoc Bonferroni test was used to determine which condition means differed. If $\log 10$ transformations did not result in normal data distribution the data was analysed using the nonparametric Kruskal-Wallis test with pre-post change data for the lung function variables. An alpha level of $P<0.05$ indicated statistical significance.

\section{RESULTS}

No significant differences were found between conditions for presession results for any lung function measure. There were no significant differences found for $\mathrm{FVC}, \mathrm{SVC}, \mathrm{FEV}_{1}, \mathrm{FEV}_{3}, \mathrm{FEV}_{6}$, ERV, and MVV between pre- and postsession for the control, 2-SETS, and 5-SETS (Table 1). A greater increased in $\mathrm{FEV}_{1} / \mathrm{FVC}$ was found following the 5-SETS compared to 2-SETS $(P=0.033)$, with a trend approaching significance when compared to the control session $(P=0.071)$. A significant reduction in IC was observed 
Hackett $D$ - Acute effects of resistance exercise on lung function

Table 1. Lung function measures pre- and postcontrol, low-volume and high-volume sessions

\begin{tabular}{|c|c|c|c|c|c|c|}
\hline \multirow{2}{*}{ Variable } & \multicolumn{2}{|c|}{ Control } & \multicolumn{2}{|c|}{ Low-volume } & \multicolumn{2}{|c|}{ High-volume } \\
\hline & Pre & Post & Pre & Post & Pre & Post \\
\hline $\mathrm{FVC}(\mathrm{L})$ & $5.3(4.9-5.7)$ & $5.4(4.8-5.7)$ & $5.4(4.9-5.8)$ & $5.5(4.8-5.8)$ & $5.5(4.8-5.8)$ & $5.2(4.7-5.8)$ \\
\hline $\mathrm{FEV}_{1}(\mathrm{~L} / \mathrm{sec})$ & $4.6 \pm 0.6$ & $4.5 \pm 0.6$ & $4.6 \pm 0.6$ & $4.6 \pm 0.6$ & $4.6 \pm 0.6$ & $4.5 \pm 0.6$ \\
\hline $\mathrm{FEV}_{1} / \mathrm{FVC}(\%)$ & $88.2 \pm 6.7$ & $88.0 \pm 6.4$ & $88.0 \pm 6.4$ & $87.4 \pm 6.3$ & $86.5 \pm 6.4$ & $89.2 \pm 6.9^{\dagger}$ \\
\hline $\mathrm{FEV}_{3}(\mathrm{~L} / \mathrm{sec})$ & $5.2 \pm 0.6$ & $5.2 \pm 0.6$ & $5.2 \pm 0.7$ & $5.2 \pm 0.6$ & $5.3 \pm 0.6$ & $5.2 \pm 0.6$ \\
\hline $\mathrm{FEV}_{6}(\mathrm{~L} / \mathrm{sec})$ & $5.4(4.9-5.7)$ & $5.4(4.9-5.7)$ & $5.4(4.9-5.8)$ & $5.4(4.8-5.7)$ & $5.5(4.8-5.8)$ & $5.2(4.7-5.8)$ \\
\hline $\operatorname{SVC}(\mathrm{L})$ & $5.6 \pm 0.7$ & $5.6 \pm 0.8$ & $5.5 \pm 0.6$ & $5.4 \pm 0.6$ & $5.5 \pm 0.6$ & $5.3 \pm 0.6$ \\
\hline$I C(L)$ & $4.2 \pm 0.5$ & $4.2 \pm 0.7$ & $4.1 \pm 0.4$ & $4.1 \pm 0.4$ & $4.2 \pm 0.4$ & $4.0 \pm 0.6^{*}$ \\
\hline ERV (L) & $1.6 \pm 0.5$ & $1.7 \pm 0.6$ & $1.6 \pm 0.4$ & $1.5 \pm 0.5$ & $1.6 \pm 0.5$ & $1.5 \pm 0.4$ \\
\hline MV (L/min) & $193.2 \pm 26.4$ & $196.4 \pm 22.5$ & $197.3 \pm 27.1$ & $197.4 \pm 27.5$ & $200.5 \pm 25.2$ & $198.9 \pm 25.8$ \\
\hline
\end{tabular}

Values are presented as median (range) or mean \pm standard deviation.

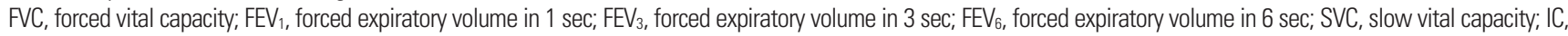
inspiratory capacity; ERV, expiratory reserve volume; MV, maximum voluntary ventilation.

*Significantly different compared to control $(P<0.05)$. 'Significantly different compared to low-volume $(P<0.05)$.
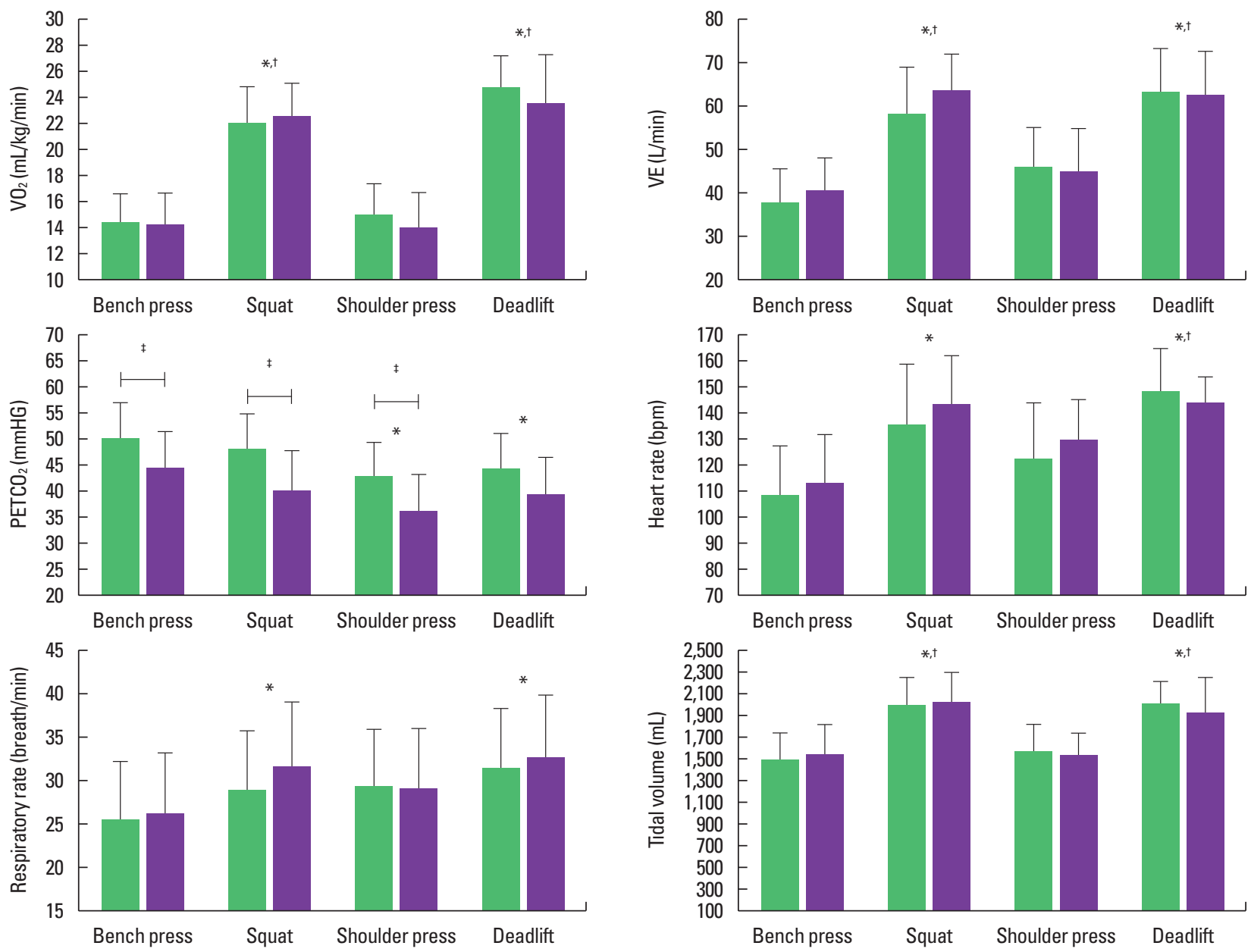

Fig. 1. Recovery responses for each exercise during the high-volume vs. low-volume session. $\mathrm{VO}_{2}$, oxygen uptake; $\mathrm{VE}$, minute ventilation; $\mathrm{PETCO}_{2}$, partial pressure of end-tidal carbon dioxide. Green bars indicate low-volume session; purple bars indicate high-volume session. * Significant difference compared to bench press $(P<0.05)$. 'Significant difference compared to shoulder press $(P<0.05)$. ${ }^{\ddagger}$ Significant difference compared to low-volume $(P<0.05)$. 
following 5-SETS compared to control session $(P=0.049)$ but no difference was found compared to 2-SETS $(P>0.05)$.

Mean recovery $\mathrm{VO}_{2}, \mathrm{VE}$, and tidal volume were greater for squats compared to bench press $(P<0.001)$ and shoulder press $(P<0.001)$ (Fig. 1). Similarly, greater mean recovery $\mathrm{VO}_{2}, \mathrm{VE}$, and tidal volume were found for deadlifts compared to bench press $(P<0.001)$ and shoulder press $(P<0.001)$. Mean respiratory rate was higher for squat and deadlift compared to bench press $(P=0.013$ and $P<0.001$, respectively). Mean recovery heart rate was higher during deadlifts compared to bench press $(P<0.001)$ and shoulder press $(P=0.024)$. Higher heart rates were also found for squats compared to bench press $(P<0.001)$. The mean recovery PETCO $_{2}$ was lower during the shoulder press compared to bench press $(P=0.001)$ and for deadlift compared to bench press $(P=0.045)$. During the 5-SETS there was a lower $\mathrm{PETCO}_{2}$ for the bench press $(P=0.013)$, squat ( $P=0.003)$, shoulder press $(P=0.008)$, and a trend was found with deadlift $(P=0.082)$ (Fig. 1). There were no other significant differences between the 2-SETS and 5-SETS for $\mathrm{VO}_{2}$, VE respiratory rate, tidal volume, and heart rate.

Session duration was greater for 5-SETS (66.4 $\pm 12.7 \mathrm{~min})$ compared to 2-SETS $(21.4 \pm 3.7 \mathrm{~min})(P<0.001)$. Total training volume was significantly greater for 5 -SETS $(13,235.4 \pm 1,939.9 \mathrm{~kg})$ compared to 2-SETS $(5,518.2 \pm 762.3 \mathrm{~kg})(P<0.001)$. For each individual exercise (bench press, squat, shoulder press, and deadlift) training volume was greater during 5-SETS $(P<0.001)$. The full 10 repetitions could be completed for $98.6 \%$ of the assigned sets for 2-SETS compared to $87.5 \%$ of sets for 5 -SETS. For individual exercises during 5 -SETS participants performed $<10$ repetitions for the shoulder press during $22.9 \%$ of sets, followed by bench press (12.9\%), squat, and deadlift (both 7.1\%).

\section{DISCUSSION}

In resistance-trained males, the present study showed there were minimal alterations in lung function following low-volume and high-volume whole-body resistance exercise sessions. There was a slight improvement in $\mathrm{FEV}_{1} / \mathrm{FVC}$ following 5 -SETS compared to 2-SETS. In contrast, IC was diminished following 5-SETS compared to the control session suggestive of respiratory muscle fatigue. Although, there were no other differences found between conditions for all other lung function measures which is in disagreement with the original hypothesis. Greater physiological demands were found for both the squat and deadlift compared to the upper body exercises as indicated by accentuation of the $\mathrm{VO}_{2}$, ventilatory pa- rameters, and heart rate responses for the former exercises. However, there was higher metabolic stress observed during the high-volume session as indicative by the lower $\mathrm{PETCO}_{2}$ observed following most exercises during the 5-SETS compared to 2-SETS. Additionally, the strenuous nature of the high-volume session was evident from a larger percentage of participants being unable to complete the desired number of repetitions during exercises. Based on the present study findings it appears that lung function remains relatively stable following an acute physically demanding resistance training bout in resistance-trained males.

It was previously unknown whether lung function would be affected by a more metabolically demanding resistance training bout. The finding of greater $\mathrm{FEV}_{1} / \mathrm{FVC}$ following the high-volume compared to low-volume session suggests mild bronchodilation that facilitated increased air flow without a significant increase in airway resistance. A possible explanation could be the increased metabolic demand of the higher volume session acutely improving smooth muscle and bronchial compliance (Milanese et al., 2009; Tipton et al., 2017). Although, it was also observed that IC was diminished following the high-volume session compared to the control session which provides evidence that inspiratory muscle function was acutely impaired. The main inspiratory muscle is the diaphragm (Enright et al., 2006), and this muscle together with other respiratory muscles assists with stabilisation of the trunk during exercises with high axial loading such as deadlifts and squats (Aasa et al., 2019). The high-volume session most likely required slightly greater work to be accomplished by the inspiratory muscles from the perspective of ensuring adequate trunk stabilisation, thus leading to inspiratory muscle fatigue. Previously Gomez et al. (2009) found that sit-ups performed to volitional fatigue resulted in diminished respiratory muscle strength while indices of lung function remained unaffected. Therefore, supporting the theory that fatigue of the respiratory muscles can be induced without high ventilatory demands for sustain periods which seems to be the main culprit contributing to respiratory muscle fatigue following aerobic exercise (Romer and Polkey, 2008).

Impairment in lung function has been reported following a CrossFit session (Shaw et al., 2015) as well as following marathon and ultramarathon running (Tiller, 2019). Aerobic exercise is associated with higher $\mathrm{VO}_{2}$ and $\mathrm{VE}$ responses compared to resistance exercise, which is considered to be an anaerobic exercise (Vilaça-Alves et al., 2016). During resistance training, peak $\mathrm{VO}_{2}$ and $\mathrm{VE}$ occur in the recovery between sets of an exercise as opposed to during the actual exercise, and then it plummets back down to pre-exercise $\mathrm{VO}_{2}$ and VE (Scott, 2011; Scott et al., 2009). The intermit- 
tent nature of resistance exercise means that $\mathrm{VO}_{2}$ and $\mathrm{VE}$ are not elevated to levels significantly above pre-exercise values for sustained periods, unlike aerobic exercise. However, during strenuous resistance exercise VE will increase disproportionately in relation to $\mathrm{VO}_{2}$ due to its relatively large anaerobic component (lactate accumulation) increased carbon dioxide and subsequent $\mathrm{H}^{+}$concentrations (De Sousa et al., 2012; Lühker et al., 2017).

In the present study, a hyperventilatory response was demonstrable through decreases in $\mathrm{PETCO}_{2}$ following each exercise. Since recovery $\mathrm{PETCO}_{2}$ was significantly lower for the 5-SET compared to 2-SET there is further evidence of greater respiratory muscle demands during the high-volume resistance training bout (Romer and Polkey, 2008). It was hypothesized that the increased ventilatory demands (i.e., hyperventilation) coupled with the requirements of the abdominals to maintain trunk stability during the highvolume session would increase the work performed by the respiratory muscles, thus leading to alterations in indices of lung function (Aliverti, 2016). However, the respiratory demands during the high-volume session were likely insufficient to impair lung function since there was no difference between the 5-SETS and 2-SETS for any lung function parameter.

Minimal improvements in lung function indices have been shown following resistance training of moderate-high volume ( $2-4$ sets per exercise) and intensity (60\%-80\% 1RM) within healthy adults (Khosravi et al., 2013). In this previous study, MVV was the only lung function parameter which improved following resistance training. The MVV test is commonly used to assess the strength and endurance of the inspiratory and expiration muscles (Green et al., 2002). Due to the diminishment in respiratory muscles strength found by Gomez et al. (2009) following sit-ups to volitional fatigue, if respiratory muscle strength was adversely affected following the high-volume session it is reasonable to assume that MVV performance would also be affected. However, it has been argued that while respiratory muscle strength is important for sustaining ventilation, performance in the MVV test is influenced by many factors (e.g., respiratory system mechanics and respiratory muscle endurance) (Neufeld et al., 2018), therefore a reduction in respiratory muscle strength may not affect MVV performance. This might also explain why other lung function indices were unaffected following the high-volume session. In other words, unless respiratory muscle strength is severely affected as a result of a chronic condition (Fitting, 2001; Singer et al., 2011) or extremely demanding exercise session (e.g., marathon run) (Tiller, 2019), lung function parameters would remain relatively stable, as was found within the present study. Other factors that influence lung function include the compliance of the lungs, condition of the ventilatory control systems, and resistance of both airways and tissues (Ionescu et al., 2009; Lalley, 2013). Although these factors are unlikely to affect lung function in healthy young adults following exercise performed at lower ventilatory demands than intense or sustained aerobic exercise.

Powerlifters have been shown to possess greater diaphragm mass and respiratory muscle strength compared to untrained healthy adults (Brown et al., 2013). Furthermore, the effectiveness of resistance training on respiratory muscle strength has been confirmed in apparently healthy (DePalo et al., 2004) and clinical populations (Menezes et al., 2016). Therefore, based on training adaptation theories an adequate training stimulus to promote improvement in lung function would present as an acute decrease in lung function (Cunanan et al., 2018). It is possible that the resistance-trained participants could cope with very demanding resistance exercise sessions without experiencing alterations in lung function postexercise due chronic training adaptations to their respiratory systems (Brown et al., 2013; DePalo et al., 2004). Further, potentially a ceiling effect may have resulted in no further improvements in lung function following attaining a certain level of resistance training experience. If an untrained population was used within the present study instead of a resistance-trained group, the effect of the high-volume resistance training session on lung function may have been different. Greater improvements in lung function were found in healthy previously inactive subjects following aerobic training combined with resistance training compared to resistance training alone (Khosravi et al., 2013). Therefore, resistance training might be efficacious for improving respiratory muscle strength, while aerobic training, either alone or in combination with resistance training seems to be most effective for improving lung function in healthy adults.

This study revealed that lung function was largely unaffected within a group of experienced male resistance trainers following a high-volume compared to a low-volume whole-body resistance exercise session. The physical demands of the high-volume session appeared insufficient to lead to any change in lung function compared to the low-volume session. Training adaptations to the respiratory system might have protected resistance trainers from experiencing reductions in lung function following the high-volume session. Another possibility is that resistance exercise is less likely to acutely affect lung function following a strenuous training session compared to intense aerobic exercise. 


\section{CONFLICT OF INTEREST}

No potential conflict of interest relevant to this article was reported.

\section{REFERENCES}

Aasa U, Bengtsson V, Berglund L, Öhberg F. Variability of lumbar spinal alignment among power- and weightlifters during the deadlift and barbell back squat. Sports Biomech 2019;1-17.

Aliverti A. The respiratory muscles during exercise. Breathe (Sheff) 2016; 12:165-168.

Bird SP, Tarpenning KM, Marino FE. Designing resistance training programmes to enhance muscular fitness: a review of the acute programme variables. Sports Med 2005;35:841-851.

Brown PI, Venables HK, Liu H, de-Witt JT, Brown MR, Faghy MA. Ventilatory muscle strength, diaphragm thickness and pulmonary function in world-class powerlifters. Eur J Appl Physiol 2013;113:2849-2855.

Cunanan AJ, DeWeese BH, Wagle JP, Carroll KM, Sausaman R, Hornsby WG, Haff GG, Triplett NT, Pierce KC, Stone MH. The general adaptation syndrome: a foundation for the concept of periodization. Sports Med 2018;48:787-797.

De Sousa N, Magosso R, Pereira G, Souza M, Vieira A, Marine D, Perez S, Baldissera V. Acute cardiorespiratory and metabolic responses during resistance exercise in the lactate threshold intensity. Int J Sports Med 2012;33:108-113.

DePalo VA, Parker AL, Al-Bilbeisi F, McCool FD. Respiratory muscle strength training with nonrespiratory maneuvers. J Appl Physiol 2004;96:731734 .

Enright SJ, Unnithan VB, Heward C, Withnall L, Davies DH. Effect of high-intensity inspiratory muscle training on lung volumes, diaphragm thickness, and exercise capacity in subjects who are healthy. Phys Ther 2006;86:345-354

Ferland P-M, Pollock A, Swope R, Ryan M, Reeder M, Heumann K, Comtois AS. The relationship between physical characteristics and maximal strength in men practicing the back squat, the bench press and the deadlift. Int J Exerc Sci 2020;13:281-297.

Fitting J. Respiratory muscles in chronic obstructive pulmonary disease. Swiss Med Wkly 2001;131:483-486.

Gomez CL, Strongoli LM, Coast JR. Repeated abdominal exercise induces respiratory muscle fatigue. J Sci Med Sport 2009;8:543.

Green M, Road J, Sieck G, Similowski T. Tests of respiratory muscle strength. Am J Respir Crit Care Med 2002;166:528-547.

Ionescu CM, Segers P, De Keyser R. Mechanical properties of the respiratory system derived from morphologic insight. IEEE Trans Biomed
Eng 2009;56:949-959.

Johnson JD, Theurer WM. A stepwise approach to the interpretation of pulmonary function tests. Am Fam Physician 2014;89:359-366.

Kang J, Hoffman JR, Im J, Spiering BA, Ratamess NA, Rundell KW, Nioka

S, Cooper J, Chance B. Evaluation of physiological responses during recovery following three resistance exercise programs. J Strength Cond Res 2005;19:305-309.

Khosravi M, Tayebi SM, Safari H. Single and concurrent effects of endurance and resistance training on pulmonary function. Iran J Basic Med Sci 2013;16:628-634.

Kraemer WJ, Ratamess NA. Fundamentals of resistance training: progression and exercise prescription. Med Sci Sports Exerc 2004;36:674688.

Krieger JW. Single versus multiple sets of resistance exercise: a meta-regression. J Strength Cond Res 2009;23:1890-1901.

Krieger JW. Single vs. multiple sets of resistance exercise for muscle hypertrophy: a meta-analysis. J Strength Cond Res 2010;24:1150-1159.

Lalley PM. The aging respiratory system: Pulmonary structure, function and neural control. Respir Physiol Neurobiol 2013;187:199-210.

Lazovic B, Mazic S, Suzic-Lazic J, Djelic M, Djordjevic-Saranovic S, Durmic T, Zikic D, Zugic V. Respiratory adaptations in different types of sport. Eur Rev Med Pharmacol Sci 2015;19:2269-2274.

Lühker O, Berger MM, Pohlmann A, Hotz L, Gruhlke T, Hochreiter M. Changes in acid-base and ion balance during exercise in normoxia and normobaric hypoxia. Eur J Appl Physiol 2017;117:2251-2261.

Martuscello JM, Nuzzo JL, Ashley CD, Campbell BI, Orriola JJ, Mayer JM. Systematic review of core muscle activity during physical fitness exercises. J Strength Cond Res 2013;27:1684-1698.

Menezes KK, Nascimento LR, Ada L, Polese JC, Avelino PR, Teixeira-Salmela LF. Respiratory muscle training increases respiratory muscle strength and reduces respiratory complications after stroke: a systematic review. J Physiother 2016;62:138-144.

Milanese M, Saporiti R, Bartolini S, Pellegrino R, Baroffio M, Brusasco V, Crimi E. Bronchodilator effects of exercise hyperpnea and albuterol in mild-to-moderate asthma. J Appl Physiol 2009;107:494-499.

Neufeld EV, Dolezal BA, Speier W, Cooper CB. Effect of altering breathing frequency on maximum voluntary ventilation in healthy adults. BMC Pulm Med 2018;18:89.

Paoli A, Gentil P, Moro T, Marcolin G, Bianco A. Resistance training with single vs. multi-joint exercises at equal total load volume: effects on body composition, cardiorespiratory fitness, and muscle strength. Front Physiol 2017;8:1105-1105.

Radaelli R, Fleck SJ, Leite T, Leite RD, Pinto RS, Fernandes L, Simão R. Dose-response of 1,3 , and 5 sets of resistance exercise on strength, local muscular endurance, and hypertrophy. J Strength Cond Res 


\section{5;29:1349-1358.}

Ratamess NR, Alvar BA, Evetoch TK, Housh TJ, Kibler WB, Kraemer WJ, Triplett NT. American College of Sports Medicine position stand. Progression models in resistance training for healthy adults. Med Sci Sports Exerc 2009; 41:687-708.

Romer LM, Polkey MI. Exercise-induced respiratory muscle fatigue: implications for performance. J Appl Physiol 2008;104:879-888.

Scott CB. Quantifying the immediate recovery energy expenditure of resistance training. J Strength Cond Res 2011;25:1159-1163.

Scott CB, Croteau A, Ravlo T. Energy expenditure before, during, and after the bench press. J Strength Cond Res 2009;23:611-618.

Shaw SB, Dullabh M, Forbes G, Brandkamp JL, Shaw I. Analysis of physiological determinants during a single bout of CrossFit. Int J Perform Anal Sport 2015;15:809-815.

Singer J, Yelin EH, Katz PP, Sanchez G, Iribarren C, Eisner MD, Blanc PD. Respiratory and skeletal muscle strength in COPD: impact on exercise capacity and lower extremity function. J Cardiopulm Rehabil Prev 2011;31:111-119.

Strasser B, Siebert U, Schobersberger W. Effects of resistance training on respiratory function in patients with chronic obstructive pulmonary disease: a systematic review and meta-analysis. Sleep Breath 2013;17: 217-226.

Tiller NB. Pulmonary and respiratory muscle function in response to marathon and ultra-marathon running: a review. Sports Med 2019;49: 1031-1041.

Tipton MJ, Kadinopoulos P, de Sa DR, Barwood MJ. Changes in lung function during exercise are independently mediated by increases in deep body temperature. BMJ Open Sport Exerc Med 2017;3:e000210e000210.

Vilaça-Alves J, Freitas NM, Saavedra FJ, Scott CB, Dos Reis VM, Simão R, Garrido N. Comparison of oxygen uptake during and after the execution of resistance exercises and exercises performed on ergometers, matched for intensity. J Hum Kinet 2016;53:179-187.

Winett RA, Carpinelli RN. Potential health-related benefits of resistance training. Prev Med 2001;33:503-513.

Wirtz N, Wahl P, Kleinöder H, Mester J. Lactate kinetics during multiple set resistance exercise. J Sci Med Sport 2014;13:73-77. 